\title{
1 Supplementary documents
}

\section{S1 The comparison between the sub-model approach and Arc-Malstrøm}

3 The program of the sub-model approach is adapted from the prototype of Arc-Malstrøm. To clarify their

4 distinctions, which in turn demonstrates the novelty of this approach, we compare the sub-model approach to 5 Arc-Malstrøm on the level of theory, input and output (Table S1a). Firstly, as opposed to Arc-Malstrøm's 1D

6 static flow, the sub-model approach uses MIKE FLOOD's 2D dynamic flows (Phase II) to obtain final flood 7 predictions, while 1D static flows (Phase I) are exclusively used for identifying reduced domains as well as 8 optimised boundaries for faster 2D flow computations. As such, unlike Arc-Malstrøm's single time simulation, 9 the sub-model approach illustrates a multiple simulation process, involving different routings (1D static/2D 10 dynamic flows) considering different modelling complexities (see Table S1a) at multiple scales (basin/local 11 catchment scale), which improves the holistic modelling performance. Secondly, whereas high-resolution DEMs are required by both approaches, differences come at rainfall datasets. Arc-Malstrøm simply demands

13 a value of the total rainfall amount reflecting a uniform static rainfall, whereby Catchment Area $\times$ Rain Amount 14 is used for the calculation of runoff volumes. In contrast, 2D rainfalls datasets, that incorporates rainfall spatial 15 variations and time evolutions in the form of Time-series raster, are required by the sub-model approach. Here, 16 Eq. (2) is used for the runoff computation of the distributed static rainfall in Phase I, while MIKE FLOOD's 17 2D solver accounts for a distributed dynamic rainfall in Phase II. Lastly, for the sake of distinctions above, differences in outputs are identified as well. Arc-Malstrøm's primary outputs illustrate final flood volumes

19 (i.e. spill-over volumes and \% filled volumes) distribution maps, and its flood extent (so-called "blue spot maps”) are exclusively based on sinks' extents. However, based on MIKE FLOOD's 2D simulations, the sub-

21 model approach's final outputs illustrate dynamic 2D predictions on flood extents, depths and flow velocities within each grid-cell of high-resolution DEMs, which deliver more precise flood information as opposed to Arc-Malstrøm. In addition, to clarify further developments, module-to-module comparisons regarding the two approaches' algorithms are presented in Table S1b. Here, four major improvements are summarised: i) the sink screening 
method (VRSS) was proposed to determine computationally important sinks and their volumes for accurate network generations and its subsequent computations; ii) the link-based fast-inundation algorithm was programmed exclusively based on stream links feature class to estimate full-basin 1D flow conditions, and a simple data structure was self-established to assemble all computational information within one attribute table; iii) an iterative search procedure was developed to trace sub-impact zones relevant to target object, where the

31 self-identified connectivity and a Boolean flow condition property was used to determine optimal tracing distances; iv) the effect of basin-wise rainfall heterogeneity was addressed in i) and ii) by integrating Eq. (2).

33 Generally, substantial differences have been identified in terms of theory, inputs, outputs and algorithms used.

34 Thus, we conclude that Arc-Malstrøm and the sub-model approach are two different applications. Furthermore, we extended two comparison tests regarding the network generation in Supplementary Document S2 and the flood extent prediction in Supplementary Document S3. 


\section{Table S1a}

54 The theory, input and output comparison between the sub-model approach and Arc-Malstrøm.

\begin{tabular}{|c|c|c|c|}
\hline & & Sub-model approach & Arc-Malstrøm \\
\hline \multirow{3}{*}{ Theory } & Routings & $\begin{array}{l}\text { - } \quad \text { Phase I: 1D static flows (basin scale); } \\
\text { Phase II: 2D dynamic flows (local catchment } \\
\text { scale). }\end{array}$ & - $\quad$ 1D static flows. \\
\hline & $\begin{array}{l}\text { Modelling } \\
\text { complexities }\end{array}$ & $\begin{array}{l}\text { Phase I considers the inundation process only. } \\
\text { Thus, hydrological losses nor drainage volumes } \\
\text { are neglected; } \\
\text { Phase II allows for the inclusion of more } \\
\text { modelling complexities (i.e. infiltrations, } \\
\text { evapotranspiration and distributed roughness) } \\
\text { within each computational cell during MIKE } \\
\text { FLOOD 2D simulations. }\end{array}$ & $\begin{array}{l}\text { Arc-Malstrøm considers infiltration } \\
\text { as volume losses (Hortonian flow) } \\
\text { for each sink's mass balance } \\
\text { conservation. The drainage system is } \\
\text { not considered. }\end{array}$ \\
\hline & $\begin{array}{l}\text { Speed-up } \\
\text { mechanisms }\end{array}$ & $\begin{array}{l}\text { - Computational domain reductions for } 2 \mathrm{D} \text { flow } \\
\text { computations; }\end{array}$ & $\begin{array}{l}\text { - Simplified routing exclusively } \\
\text { governed by the conservation of } \\
\text { mass balance. }\end{array}$ \\
\hline \multicolumn{2}{|c|}{ Inputs } & $\begin{array}{l}\text { - } \quad \text { High-resolution DEMs (DHyM + DSM); } \\
\text { Distributed 2D rainfalls with the time evolution: } \\
\text { distributed static rainfall (Phase I, computed by } \\
\text { Eq. (2)) + distributed dynamic rainfall (Phase II, } \\
\text { computed by MIKE FLOOD); } \\
\text { - Target objects. }\end{array}$ & $\begin{array}{l}\text { - } \begin{array}{l}\text { High-resolution DEM (DHyM); } \\
\text { Static uniform rainfall (total rainfall } \\
\text { amount), computed by Catchment } \\
\text { Area } \times \text { Rain Amount; } \\
\text { - Distributed subsurface map } \\
\text { accounting for distributed infiltration } \\
\text { process. }\end{array} \\
\end{array}$ \\
\hline \multirow{4}{*}{ Outputs } & Types & - $\quad$ Dynamic 2D predictions. & - $\quad$ Static 1D predictions. \\
\hline & Flood extents & - $\quad$ Flood extents based on maximum flood depths. & $\begin{array}{l}\text { - Flood extents based on sink extents } \\
\text { (blue spots map). }\end{array}$ \\
\hline & Flood depths & $\begin{array}{l}\text { Maximum flood depths summarised from } \\
\text { dynamic flood depths based on each grid-cell, } \\
\text { thus capturing peak flood precisely. }\end{array}$ & $\begin{array}{l}\text { No flood depth provided; } \\
\text { Instead, final flood volumes within } \\
\text { each sink (i.e. spill-over volumes and } \\
\% \text { filled volumes) are provided. }\end{array}$ \\
\hline & Flow velocity & $\begin{array}{l}\text { - Flow velocities provided in u- and v-directions } \\
\text { based on each grid-cell. }\end{array}$ & - No flow velocity provided. \\
\hline
\end{tabular}


64 Table S1b

65 Module-to-module comparison table between the sub-model approach and Arc-Malstrøm.

\begin{tabular}{|c|c|c|c|}
\hline & & Sub-model approach & Arc-Malstrøm \\
\hline \multirow{8}{*}{$\begin{array}{l}\text { Algorithms } \\
\text { distinction for } \\
\text { each module }\end{array}$} & $\begin{array}{l}\text { Sink screening } \\
\quad \text { (Module I) }\end{array}$ & - Volume Ratio Sink Screening. & $\begin{array}{l}\text { - Sink screening criterion based on } \\
\text { sink's maximum depth, where sinks } \\
\text { less than DEMs' vertical accuracy } \\
\text { (i.e. } 0.05 \mathrm{~m} \text { ) are eliminated. } \\
\end{array}$ \\
\hline & $\begin{array}{l}\text { Network } \\
\text { generation } \\
\text { (Module II) }\end{array}$ & $\begin{array}{l}\text { - The network without using the } \\
\text { ArcGIS' geometric network data } \\
\text { structure. }\end{array}$ & $\begin{array}{l}\text { - Using ArcGIS' geometric network to } \\
\text { assemble networks. }\end{array}$ \\
\hline & \multirow{3}{*}{$\begin{array}{l}\text { Fast-inundation } \\
\text { spreading } \\
\text { algorithm } \\
\text { (Module III) }\end{array}$} & $\begin{array}{l}\text { - Computation has independency to } \\
\text { ArcGIS' geometric network; } \\
\text { - } \quad \text { Programming in Python; } \\
\text { - Computational information coded } \\
\text { on Stream Link feature class: }\end{array}$ & $\begin{array}{l}\text { Computation based on ArcGIS' } \\
\text { geometric network; } \\
\text { - } \quad \text { Programming in C\# under .Net } \\
\text { framework via ArcObject SDK; } \\
\text { - Computational information coded on }\end{array}$ \\
\hline & & $\begin{array}{l}\text { - Computing order determined by } \\
\text { Shreve order; } \\
\text { - Topological connectivity self- } \\
\text { identified by ArcGIS' Spatial Join } \\
\text { tool; }\end{array}$ & $\begin{array}{l}\text { - Computing order determined by } \\
\text { accessing point-to-point relation from } \\
\text { the geometric network's relation } \\
\text { class; } \\
\text { Topological connectivity established } \\
\text { by assessing the geometric network's } \\
\text { functions. }\end{array}$ \\
\hline & & $\begin{array}{l}\text { Computational information and } \\
\text { topological connectivity } \\
\text { configured in one table. }\end{array}$ & $\begin{array}{l}\text { - Computational information and } \\
\text { topological connectivity stored in } \\
\text { separate class objects in the geometric } \\
\text { network. }\end{array}$ \\
\hline & & $\begin{array}{l}\text { Upstream tracing based on the self- } \\
\text { identified topological connectivity; }\end{array}$ & $\begin{array}{l}\text { Upstream tracing provided based on } \\
\text { the geometric network's function; }\end{array}$ \\
\hline & $\begin{array}{l}\text { Search algorithm } \\
\quad \text { (Module IV) }\end{array}$ & $\begin{array}{l}\text { Tracing distance determined by } \\
\text { considering spill-over /non-spill- } \\
\text { over as a termination criterion for } \\
\text { the searching loop. }\end{array}$ & $\begin{array}{l}\text { Tracing distance determined from } \\
\text { topological connectivity only. }\end{array}$ \\
\hline & $\begin{array}{l}\text { 2D flow } \\
\text { computations } \\
(\text { Module V) }\end{array}$ & $\begin{array}{l}\text { 2D flow computations based on } \\
\text { MIKE FLOOD by using reduced } \\
\text { domains and optimised boundary } \\
\text { conditions. }\end{array}$ & $\times$ \\
\hline
\end{tabular}


67 S2 Comparison tests of network generations between Arc-Malstrøm and the sub-model approach.

68 To distinct networks generated by Arc-Malstrøm and the sub-model approach, by adopting the vertical 69 accuracy of $0.05 \mathrm{~m}$ and $\mathrm{HRV}_{\text {ratio }}$ of $15 \%$ as sink screening criteria, different networks were configured based 70 on the corresponding sink configurations. These networks' spatial layouts were investigated from two 71 perspectives: drainage basin discretisation (Fig. S2 a and b) and network delineations (Fig. S2 c and d). 72 Besides, their geometric properties were summarised based on geometric statistic in Table S2.

73 In contrast to Arc-Malstrøm, the sub-model approach shows intuitively simpler drainage basin discretization 74 (Fig. S2 a and b). In Table S2, substantially larger average areas of $7555 \mathrm{~m}^{2}$ and the smaller number of 9703 were observed for discretised sub-impact zones of the sub-model approach. Also, a simpler network complexity was identified for the sub-model approach compared to Arc-Malstrøm, and the smaller network density of $0.0153 \mathrm{~m}^{-1}$ and the smaller number of links $(13,559)$ were obtained. Due to the decreased number of the $1^{\text {st }}$ and $2^{\text {nd }}$ order links, the reduced Max. Shreve order of 6611 was found for the sub-model approach's network. Yet, highly densified networks were found in the northern and western parts of the Greve basin (Fig. S2 d), which is in accordance with basin-wise rainfall distributions of Thiessen polygons (Fig. 9). Here, more

81 sinks were preserved in these regions hit by smaller rainfalls, configuring more detailed networks to improve the 1D surface runoff representations. 
(a)

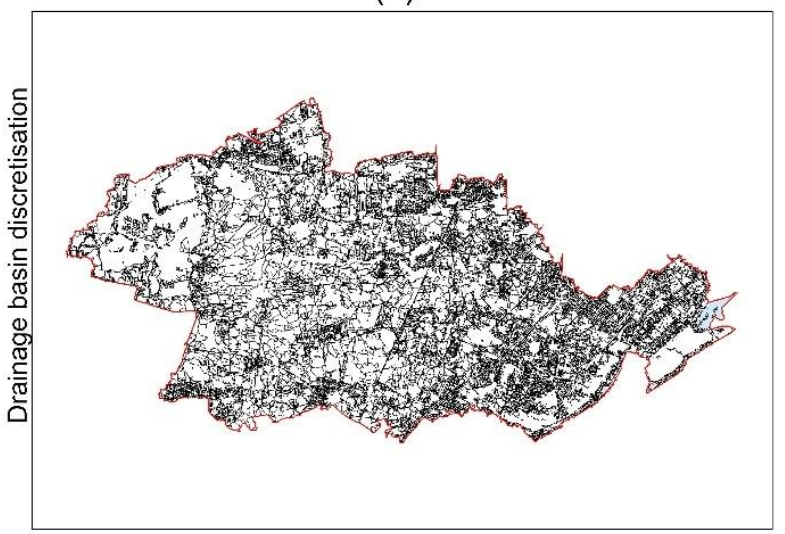

(c)

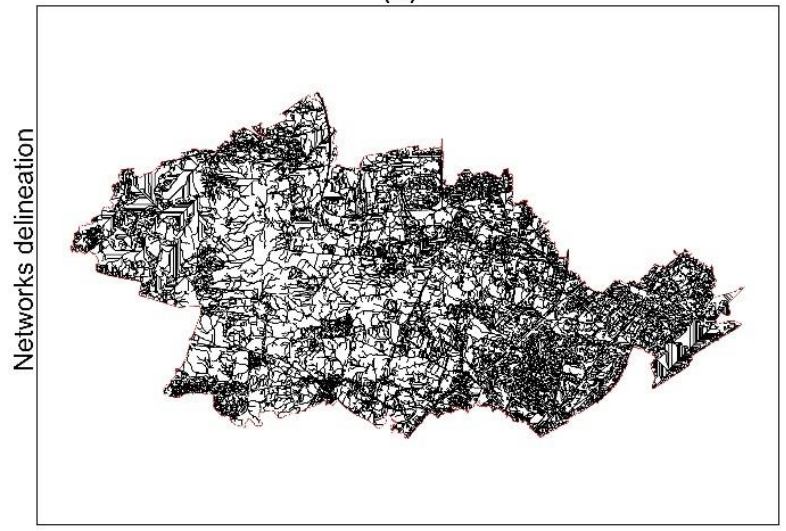

(b)

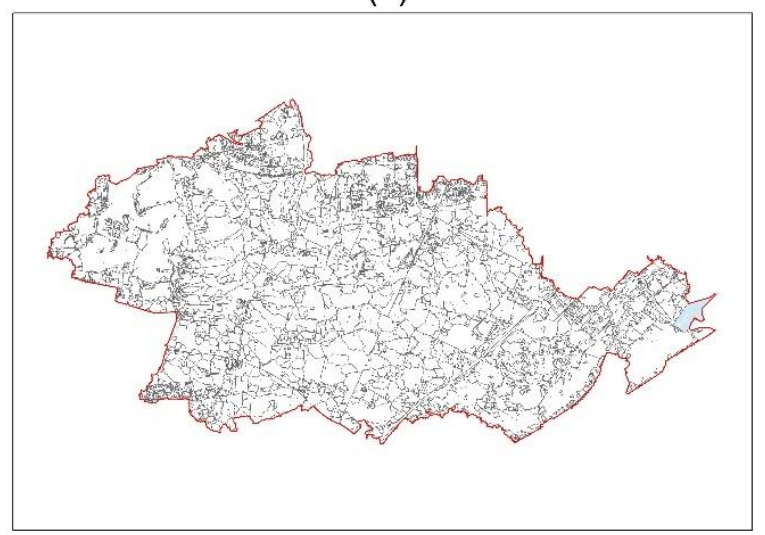

(d)

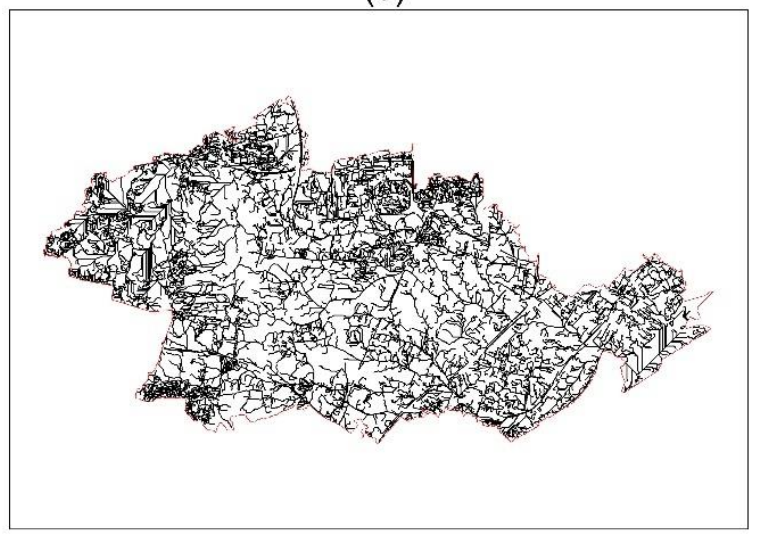

83

85

86

87

88

Table S2 Geometric statistic for network generated by Arc-Malstrøm and the sub-model approach.

\begin{tabular}{|c|c|c|c|c|}
\hline & & & $\begin{array}{c}\text { Arc-Malstrøm's } \\
\text { network }\end{array}$ & $\begin{array}{c}\text { Sub-model } \\
\text { approach's network }\end{array}$ \\
\hline \multirow{2}{*}{$\begin{array}{c}\text { Drainage basin } \\
\text { discretisation }\end{array}$} & \multicolumn{2}{|c|}{ No. of sub-impact zones } & 38131 & 9703 \\
\hline & \multicolumn{2}{|c|}{ Average areas of sub-impact zones $\left(\mathbf{m}^{2}\right)$} & 1925 & 7555 \\
\hline \multirow{9}{*}{$\begin{array}{c}\text { Network } \\
\text { delineation }\end{array}$} & \multicolumn{2}{|c|}{ Network density $\left(\mathrm{m}^{-1}\right)$} & 0.0267 & 0.0153 \\
\hline & \multicolumn{2}{|c|}{ Total length (m) } & 1990314 & 1130862 \\
\hline & \multicolumn{2}{|c|}{ Average length of links (m) } & $52 \mathrm{~m}$ & 83 \\
\hline & \multicolumn{2}{|c|}{ Links No. } & 38554 & 13559 \\
\hline & \multicolumn{2}{|c|}{ Max. Shreve order } & 18620 & 6611 \\
\hline & \multirow{2}{*}{$1^{\text {st }}$ order links } & Average length (m) & 53 & 86 \\
\hline & & Link No. & 19479 & 6849 \\
\hline & \multirow{2}{*}{$2^{\text {nd }}$ order links } & Average length (m) & 51 & 82 \\
\hline & & Link No. & 4840 & 1708 \\
\hline
\end{tabular}

Note: Network density = Total length of networks / Total drainage basin areas, which reflects the network concentration in each drainage area.

Fig. S2 Network generation comparisons between Arc-Malstrøm and the sub-model approach: (a) Arc-Malstrøm's drainage basin approach's network delineations. 
S3 Prediction results comparison tests between Arc-Malstrøm and the sub-model approach.

According to Table S1, flood extents were identified as the joint output for Arc-Malstrøm and the sub-model approach. To further distinguish their prediction discrepancies, cell-by-cell comparisons of the two approaches were conducted by using the binary analysis (dry /wet) considering four different catchment areas as well as different rainfall return periods (1-100 year), see Fig. S3. In catchment A, a goodness of fit $\left(\mathrm{F}^{2}=0.7\right)$ between the two approaches was observed, especially for the downstream areas (H2) hit by extreme rainfalls of 98.6 mm. However, underestimations (blue cells), distributing along the flow paths, were found for Arc-Malstrøm. In accordance with findings by Jahanbazi and Egger, (2014) and Jamali et al., (2018), Arc-Malstrøm (as a static model) cannot provide flood predictions beyond the location of sinks and, therefore, the flow conditions along pathways may be miss-captured. In addition, due to the different approaches to defining flood extents, the sub-model approach, delineating flood extents based on flood depths of each grid-cell, may exclude the flooded cells of $<10 \mathrm{~cm}$ inside sinks, thus resulting in discrepancies, e.g. red cells in $\mathrm{H} 1$ and $\mathrm{H} 3$. In catchment B, significant underestimations were spotted in $\mathrm{H} 4$ and $\mathrm{H} 6$ when using Arc-Malstrøm. Due to the special catchment topologies, substantially converged flow accumulations may deliver high-momentum flows throughout long propagation paths, thus reaching more areas (blue cells) beyond sink extents (light blue cells). Notable miss-predictions were identified for Arc-Malstrøm in H5. Here, the occurrence of the water ponding was ascribed to the limited discharge of the downstream highway underpass, and such flood peaks can be captured, only, during dynamic simulations. In catchments $\mathrm{C}$ and $\mathrm{D}$, significant discrepancies of $\mathrm{F}^{2}=0.30$ and 0.12 were suggested for the comparison of the two approaches. Because non-spill-over sinks present much smaller inundation extents than sink's full extents, Arc-Malstrøm overestimated flood extents substantially in case of small rainfall events. Whereas identifying a volume-depth curve for each sink may suggest more precise flood extents (Jamali et al., 2018, Zhang and Pan, 2014), it is quite challenging to identify realistic flood extents for those sinks comprising several small sinks, e.g. the sink on the right side of $\mathrm{H} 7$, and its small sinks to the left were filled first. 

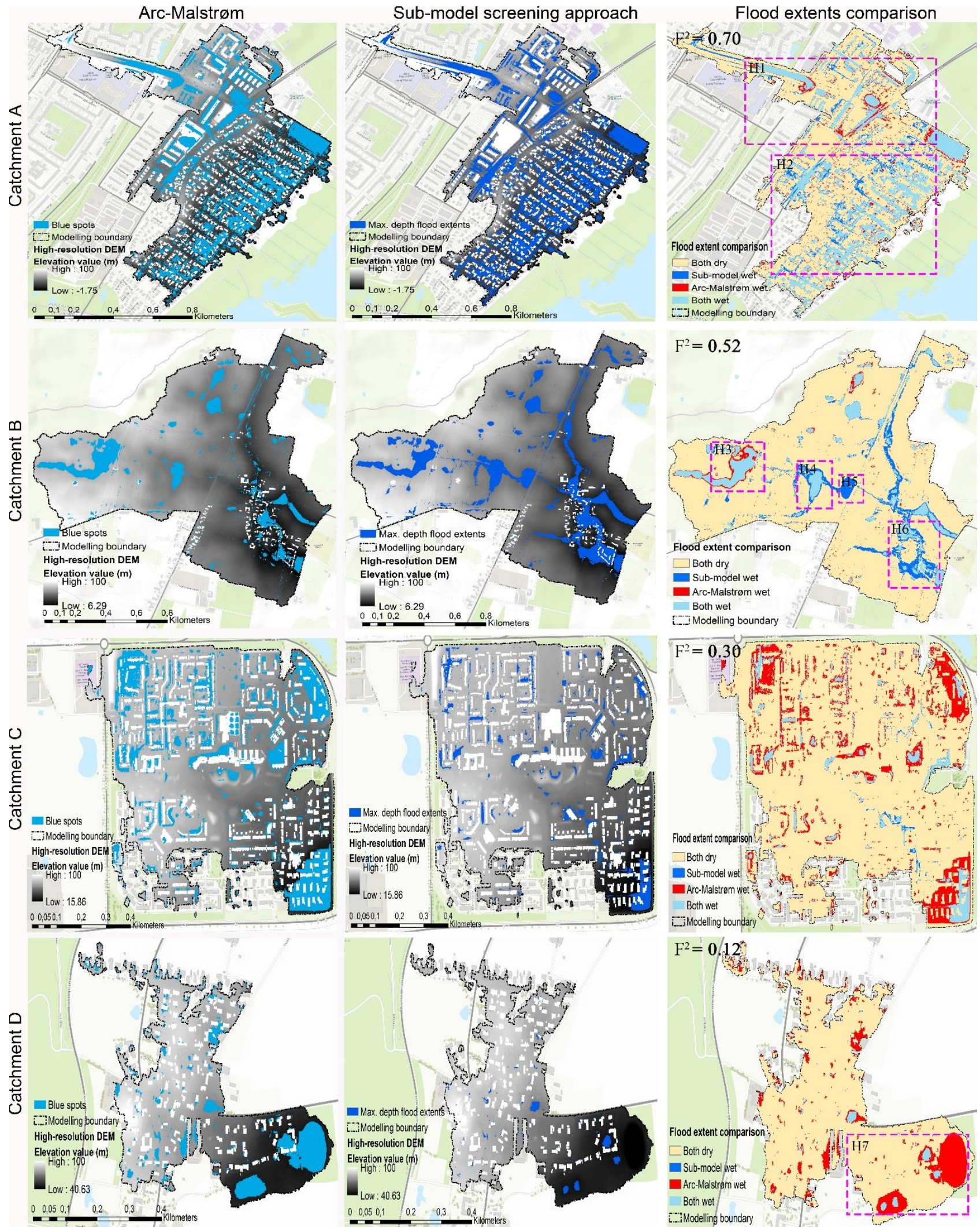

Basemap source: Esri, DigitalGlobe, GeoEye, Earthstar Geographics, CNES/Airbus DS, USDA, USGS, AEX, 724 Getmapping, Aerogrid, IGN, IGP, swisstopo, and the GIS User Community

Fig. S3 Flood extent comparisons between Arc-Malstrøm and the sub-model approach based on four catchments area representing different terrain morphologies as well as different rainfall return periods (1-100 year), where the first column represents the Arc-

Malstrøm's flood extent predictions, the second column represent the sub-model approach's flood extent predictions, and the third column is categorised maps showing the discrepancies in flood extent predictions. 
123 The comparison test using the uniform open-boundary condition are presented from the perspective of 124 maximum flood extents (Fig. S4a and b) and maximum flood depths (Fig. S4 c and d). Significant underestimations in maximum flood extents and maximum flood depths were seen for the two approaches. Due to the massive leakages of runoff volumes via the open-boundary conditions, the 2D runoffs, which were supposed to accumulate locally and then flowed into the central area, escaped directly from their closest edges. These hydraulic behaviours violated the 1D flow pattern pre-defined, thus these results were recognised as miss-predictions and must not be used for domain reduction tests.

(a)

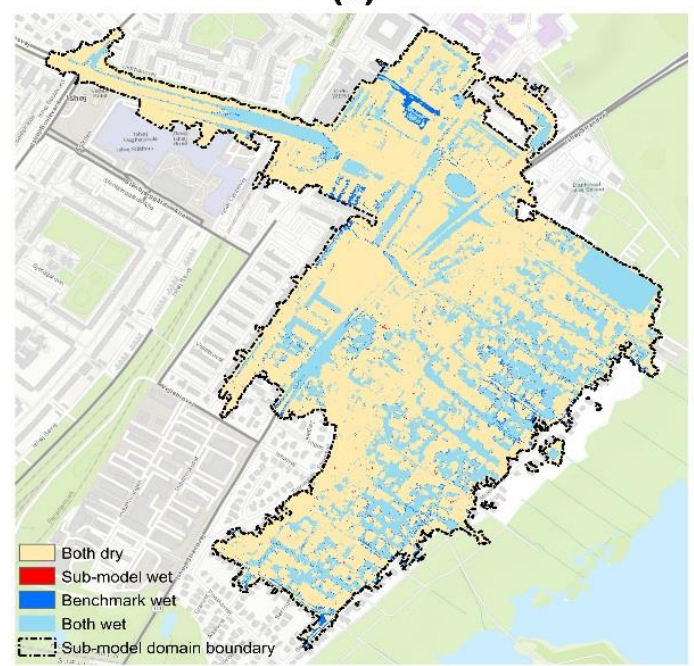

(c)

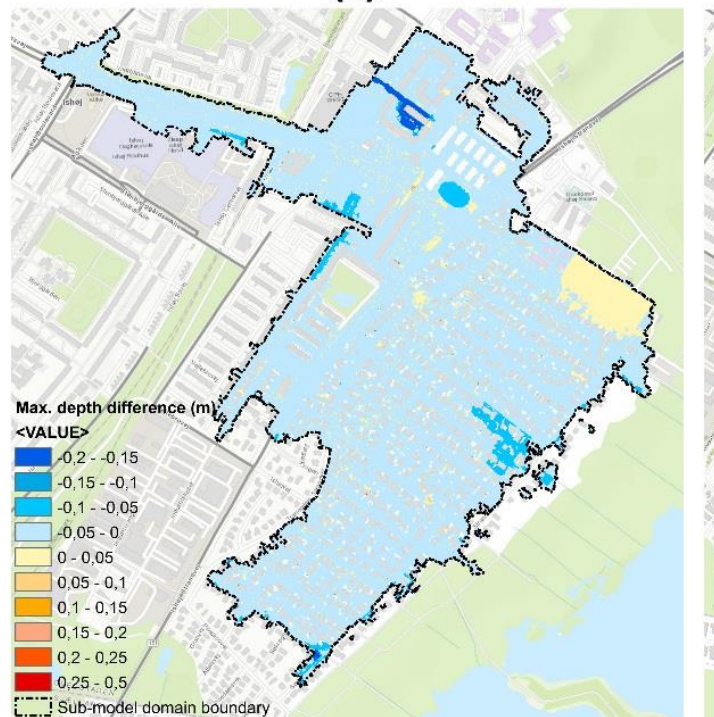

(b)

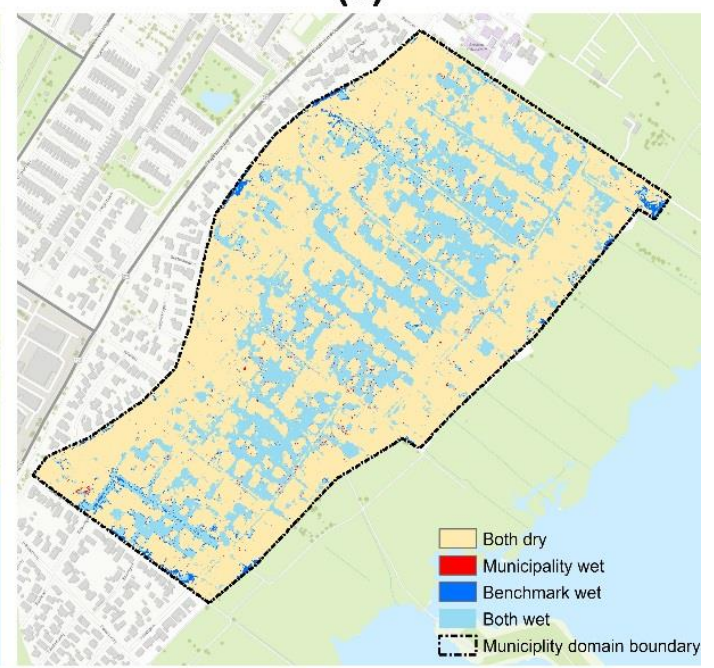

(d)

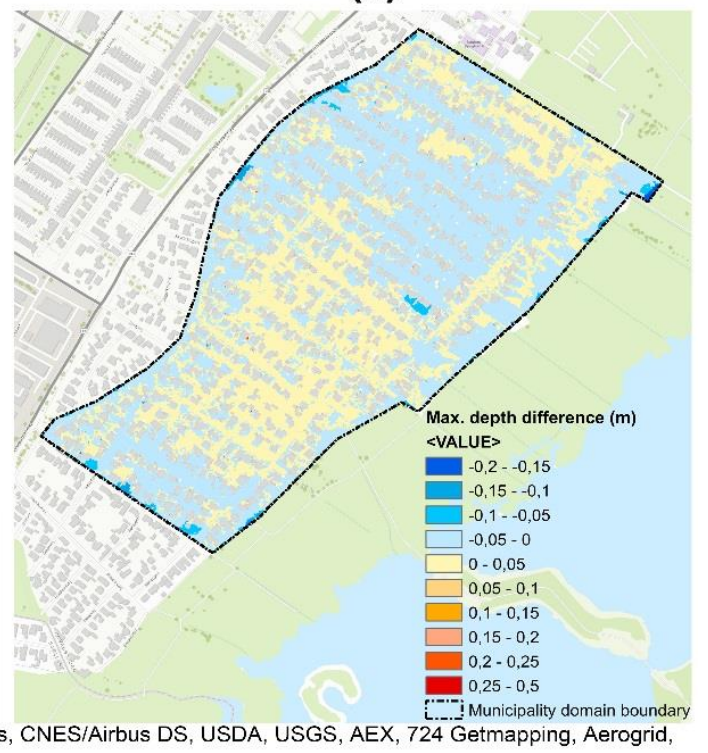

Basemap source: Esri, DigitalGlobe, GeoEye, Earthstar Geographics, CNES/Airbus DS, USDA, USGS, AEX, 724 Getmapping, Aerogrid,

GN, IGP, swisstopo, and the GIS User Community

Fig. S4 Maximum depth flood extents and maximum depth differences with the uniform open-boundary condition: (a) Sub-model approach's categorised map, (b) Municipality domain approach's categorised map, (c) Sub-model approach's depth difference map, 

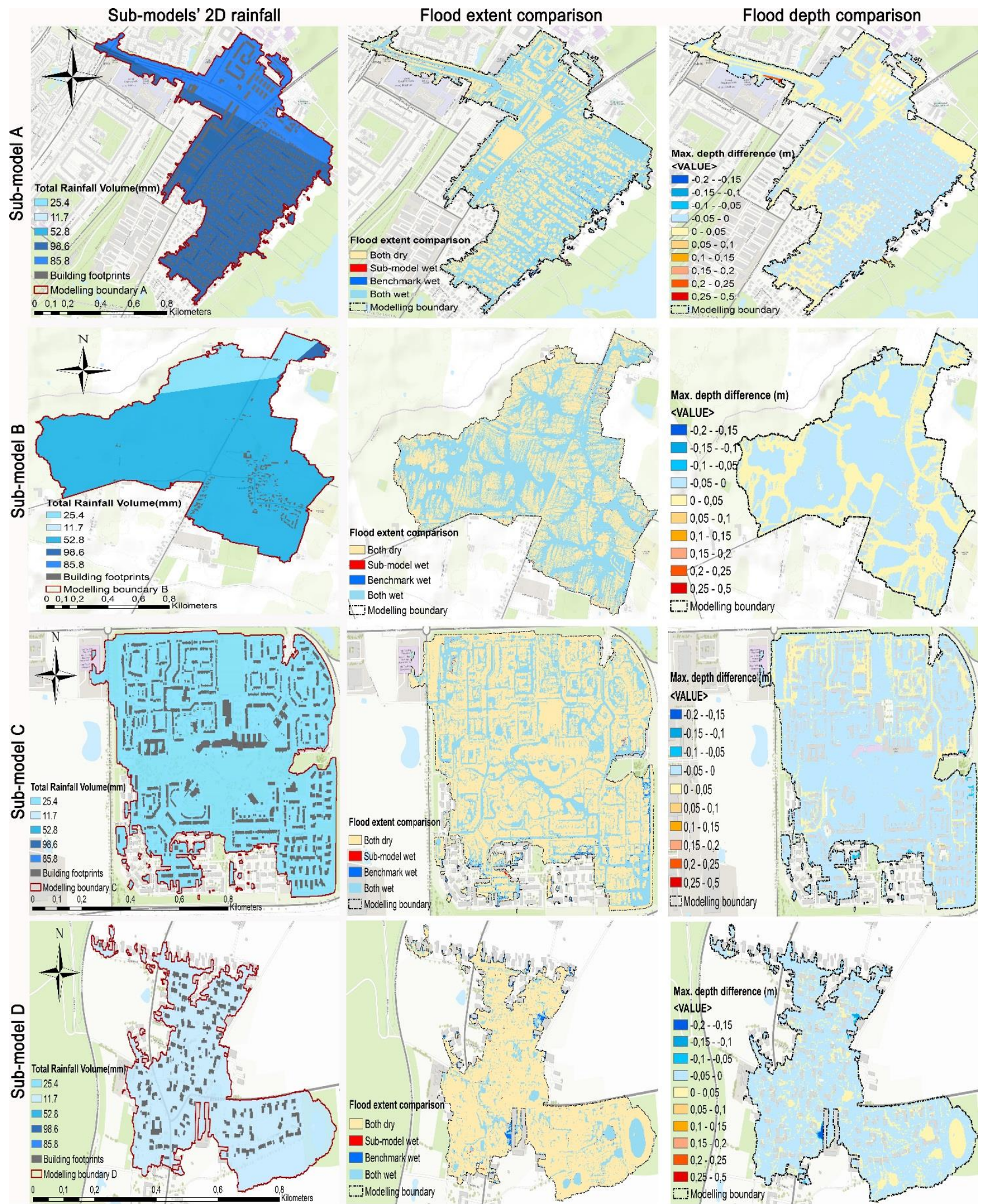

Basemap source: Esri, DigitalGlobe, GeoEye, Earthstar Geographics, CNES/Airbus DS, USDA, USGS, AEX, 724 Getmapping, Aerogrid, IGN, IGP, swisstopo, and the GIS User Community Fig. S5 The first column represents the reduced 2D rainfalls associated with different data volumes in .dfs2 file (MIKE FLOOD 2D's input file format); the second column represents maximum depth flood extent's categorised maps for four sub-models and the third column represents maximum depth's depth difference map for four sub-models. 